\title{
Television Match Officials, Referees and Home Advantage: \\ Evidence from the European Rugby Cup
}

Dr Peter Dawson ${ }^{\mathrm{a}}$

Reader in Economics

School of Economics

University of East Anglia

Norwich

Norfolk

NR4 7TJ

$\underline{\text { Peter.Dawson@uea.ac.uk }}$

email:
Patrick Massey ${ }^{\mathrm{b}}$

(Corre sponding author)

birector

Compecon Limited

37 Willowbank Park

Rathfarnham

Dublin

D14 HW70

Ireland pmassey@,compecon.ie

p.downward@lboro.ac.uk
Prof Paul Downward ${ }^{\mathrm{c}}$

cSport Policy and

Management Group

School of Sport, Exercise

and Health Sciences

Loughborough University

Leicestershire

LE11 3TU

3rd April 2019. 
Abstract: The regulation of on-field competition by officials is an important aspect of the management of sport. Increasingly, sports are providing technological support for officials to aid their decision making. In this paper, the authors analyse the impact of such an innovation by exploring the impact of the introduction and subsequent extended role of the television match official on the award of sanctionable offences of players in matches played in the group stages of the European Rugby Cup (ERC) and European Rugby Champions Cup (ERCC) over 15 seasons from 2000/01 to 2015/16. Rugby Union is an important sport to reflect upon because of the central role that the referee plays in rule interpretation and game management and the level of home advantage tends to be relatively high in the sport. Indeed, $65 \%$ of all matches in the sample analysed resulted in home wins. Results suggest that crowd effects and referee experience influence referee decisions, but the effects vary depending on the type of incident being considered. The main finding and contribution of the paper is that the introduction of the television match official has influenced the incidence of sanctions issued to both teams. However, the increase in the number of yellow cards awarded to away teams implies that home bias has increased since the introduction of the television match official. This suggests that referees may have been consciously or unconsciously seeking to avoid contributing to home bias before the introduction of a further official who is remote from the effects of the crowd. Recognising that such an adjustment takes place according to the circumstances is important information for the training of officials; particularly as a television match official may not be present in all games that they will referee.

Keywords: Team Sports; Home Advantage; Favouritism; Competition; Performance 


\section{Introduction}

Lack of bias in sporting competition has always been viewed as essential to its sustainability. This is, whether residing in the expression of necessary ethical and moral dimensions of fair play in the developments of modern sport in England (Renson, 2009), aspirations of which carry through to current codes of ethics (Council of Europe, 2010), or for more commercial needs such as the initial need to facilitate gambling as sports developed (Renson, 2009) and subsequent arguments for the need to regulate competitive balance in sports leagues to sustain their long-term economic prospects (Downward, Dawson \& Dejonghe, 2009). It is upon the latter arguments that recent policies such as UEFA's Financial Fair Play have their foundation (Peeters \& Szymanski, 2014). Officiating sports contests in a fair way has always been an essential part of these developments stemming from an initial need to ensure adherence to newly codified rules and laws of games, having authority to arbitrate on disputed actions and, importantly, to see that justice is done (Rains, 1984). However, the importance of such a role for officials has heightened with the growth in the commercialisation of sport (Webb, 2017) and this raises challenge for the management of sports competition.

Consequently, home advantage is a commonly observed feature in many team sports. Home advantage reflects a bias such that, in a balanced schedule of home and away fixtures, home teams win more than $50 \%$ of games. Along with the motivational influence of the crowd upon players, familiarity with the venue, travel factors - such as distance and duration which can fatigue away opposition- and rule factors such as who bats first have been identified as sources of bias. However, match officials are also identified as a key source of the mediation of home bias through the crowd as the latter can influence the subjective judgements of the former (Carron, Loughhead, \& Bray, 2005; Courneya \& Carron, 1992; Pollard, 2008). It is important to recognise, therefore, that this bias is not assumed to be generally associated with officiating malfeasance; rather, is a statistical outcome reflecting the context of decision-making influencing 
officials' decisions and match outcomes. For example, Rodenberg and Lim (2009) found only one case of what they describe as retribution decision making in NBA playoff games.

Nonetheless, sports are now increasingly introducing technology to aid decision making, of which the television match official is one, to help to provide a less contextually influenced decision. As Wright (2014) and Kendall and Lenten (2017) note, however, unexpected consequences can follow with organisational and rule changes in sport. Effective management and delivery of sports competitions thus requires monitoring for unintended consequences and realigning policy to account for it.

Consequently, we consider whether there were unintended consequences associated with the introduction, and subsequent extended role, of the television match official in connection to the incidence of sanctionable offences in the group stages of the European Rugby Cup (ERC) and European Rugby Champions Cup (ERCC) ${ }^{1}$ over 15 seasons from 2000/01 to 2015/16. It is the first study to examine the impact of technological monitoring of officials in rugby. The contribution and focus are upon the assumed potential of a television match official to reduce home bias through increased monitoring as suggested might be the case with their introduction by Downward and Jones (2007). Rugby union provides an important context to explore this issue because of the relatively high level of home advantage ( $65 \%$ in our sample), the greater influence of the referee compared with many other team sports (Page \& Page,2010), and the fact that rugby union has a long history of the use of a television match official.

\section{Bias and official behaviour}

\subsection{Theoretical insight}

Officials in sports contexts can be understood theoretically and structurally as acting as

\footnotetext{
${ }^{1}$ The ERC/ERCC is similar to football's UEFA Champions League, albeit with participating teams drawn from just six countries - England, France, Ireland, Italy, Scotland and Wales.
} 
an agent in a Principal-Agent relationship, in which the principal is the sport's organisational body. In a general setting, the Principal-Agent relationship involves the delegation of a task from a principal to an agent in the context of imperfect or asymmetric information such that the agent is imperfectly monitored and has the discretion to act in their own interests rather than the principal's (Laffont \& Martimort, 2002). In sport, the sports organisation seeks to ensure that the laws of the game are adhered to so that fair competition takes place.

However, it is the officials acting at the tournament that actually make the decisions about the governance of the contest. As Collins (2010) argues, during games it has been widely accepted in sport that the official's decision is final. Such (ontological) authority has traditionally been supported by the notion that the official has the (epistemological) privilege of having both a clearer view of the game through being on the field of play and, moreover, has the skills required to officiate through for example, being a prior participant in the sport, having received relevant training etc.

This delegation of authority to sports officials is, to an extent, distinct from the more general principal-agent context in which the former needs to develop incentives to ensure that the Agent acts as the Principal intends. In the context of personnel economics, therefore, a large literature has therefore developed drawing on (Lazear, 1995) in which a core recommendation is to link pay to performance. Alternatively enhanced monitoring of the relationship can be employed and has been shown to improve short-run performance, or can be linked to longer run human resource development (Taylor \& Tyler, 2012). However, increased monitoring has also been argued to be detrimental to delivering outcomes by increasing the stress and pressure to perform by agents (Parsons, Sulaeman, Yates, \& Hamermesh, 2011) or by reducing their trust (Frey, 1993).

In sport it is the monitoring of officials that is potentially of most relevance as performance related pay is largely absent, though it has been shown that a movement from 
short-term to salaried contracts improved official decision making (Bryson, Buraimo, \& Simmons, 2011). However, there is no strong evidence on the effectiveness of monitoring of officials by sports organisations, though as noted above, scrutiny and monitoring of officials is not just undertaken by sports organisations but also by crowds, which can influence officials (Mascarenhas, Collins, \& Mortimer, 2005).

Theoretically, an economic interpretation of this process by which crowds influence officials' decisions could be that preferences are endogenous and influenced by social contextual behaviour (Garicano, Palacios-Huerta, \& Prendergast, 2005). In psychological terms this might be because crowd noise acts as a cue to the interpretation of a situation, involving players or outcomes on the field. As these monitoring cues are likely to be biased, then the official's decisions may become shaped to reflect this prevailing sentiment (Unkelbach \& Memmert, 2010). As sports require rapid and time constrained decisions in a context that lacks opportunity for complex evaluations then it is likely that officials will focus on salient cues such as crowd noise (Nevill, Balmer, \& Williams, 2002; Page \& Page, 2010).

Implicit preferences might also underpin favouritism, though the bias may be unconscious. Insights into favouritism within a Principal-Agency framework are provided by Prendergast and Topel (1996). They find that subjectivity may lead to supervisors rewarding (punishing) preferred(less preferred) workers. Social identity, such as shared national identity and beliefs (based on prior experience, for example), have been recognised as key sources of favouritism. In sport, such preferences might reflect the incidence of greater contact between particular teams and officials (Hlasny \& Kolaric, 2017). Moreover, in this context, clearly national, or sporting allegiance could potentially influence officials (Dawson \& Dobson, 2010). However, it is also argued that decision making can be affected by the decision-maker's level of experience (Garside, Grout, \& Zalewska, 2013).

The key focus of attention in this paper is upon the introduction and enhanced role of the 
television match official as a monitoring device. As noted above, in general it is unclear what the outcome of increased monitoring might be. In sports, Collins (2010) notes that the introduction of additional monitoring to a traditional structure of decision making can:

degrade the epistemological privilege of the umpire and referee...the epistemological privilege has moved to the crowd or the remote television viewer. This often means that there is disharmony between the ontological authority and the epistemological privilege leading to loss of credibility of the match official (Collins, 2010 p. 136)

Consequently, it is important to examine what the implications of these changes might be for officials' decisions. As noted below, empirical insight into the role of additional monitoring is relatively limited.

\subsection{Empirical insight}

Since the earlier work of Courneya and Carron (1992), Dohmen and Sauermann (2016) cite a well-developed literature which addresses the related concepts of home advantage and referee bias in sports. Nevill and Holder (1999) conclude that the weight of evidence indicates that the crowd is the main source of home advantage and that this is largely due to the effects of the crowd on referees. Consequently in an experimental study Nevill, Hemingway, Greaves, Dallaway, and Devonport (2017) show that compared to football referees with no fans present in a room when reviewing actual referee decisions of the 2016 Champion's league final, football referees disagreed with the actual referee less when fans were present. However, the disagreements favoured the team whose fans were present. Moreover, Trandel and Maxcy (2011) attribute differences in home advantage between US sports in part to the fact that crowds sit closer to players and officials in arena sports such as basketball and ice hockey than they do in (primarily) outdoor sports.

A number of forms of referee bias are explored in the literature. Nevill et al., (2002) find 
that in an English Premier League match between Liverpool (home) and Leicester City (away) from the 1998/1999 season, referees are likely to treat the tackles made by the home team more leniently when exposed to the effects of crowd noise. Sutter and Kocher (2004) found that referees added more extra time and awarded more penalties in favour of the home team, when it was behind, in the German Bundesliga and the Spanish Primera Liga. Garicano et al., (2005) moreover report a positive relationship between crowd size and referee bias in favour of the home team in Spanish football through referees adding more time to games and reducing extra time in games when the home team is behind or in front respectively. Garicano et al., (2005) control in their analysis for the possession of yellow and red-cards by teams. The sanction of players through the awarding of cards has also, however, been researched.

As well as awarding more penalties in favour of the home team Boyko, Boyko, and Boyko (2007) find that English Premier League football referees also awarded more yellow and red cards for the away team than the home team and argue that crowd size influences this result, though it varies across different referees. Studies by Buraimo, Forrest, and Simmons (2010) and Buraimo, Simmons, and Maciaszczyk (2012) focussing on matches in the English Premier League and Bundesliga, and Primera Liga in Spain and Champions League matches respectively, identify that the award of yellow cards and red cards, and the award of yellow cards favours the home team. Significantly they identify that in situations in which the pitch is surrounded by a running track home advantage is less. This is evidence of reduced crowd impacts on referee decisions.

In contrast Reilly and Witt (2013) find that whilst there is evidence of home bias in the award of red cards in the English Premier League, crowd size does not influence the results. Likewise Dawson, Dobson, Goddard, and Wilson (2007) also analyse the English Premier League and identify that the away teams incur more disciplinary sanction in the form of red and yellow cards than home teams, controlling for their relative strength and crowd size, the latter of 
which does not influence the results. Heterogenous behaviour across referees is also identified. Such heterogeneity is also identified by Dawson and Dobson (2010) who examine European cup football matches. Specifically, referee and team nationality is important in understanding referee bias as well as crowd density, stadium architecture and the stage of the competition. Dawson (2012) does show, however, that referee experience can ameliorate some of the bias.

Downward and Jones (2007), moreover, analyse data on yellow cards issued in matches in English football's F.A. Cup finding that crowd size affected the degree of referee bias in favour of the home team. They also show that the effects are non-linear as they diminish with larger crowds. This is attributed to larger crowds being more balanced at neutral venues in the latter stages of the competition. They are also the first to suggest that consideration should be given to using 'video referees' (i.e. television match officials) deployed outside the ground, and away from the influence of the crowd, for crucial match-changing decisions.

Support for the non-linear effect of crowd sizes is also provided by Pollard (1986) and Clarke and Norman (1995) who both show that home advantage was lower in English football matches between London based clubs which they attribute to attendances being more evenly balanced in such matches. Jones, Bray, and Bolton (2001) also report no evidence of official bias in English minor league cricket where average attendances are less than 50.

Finally, focussing on the chances of winning games in the Bundesliga and Major League Soccer, rather than within-game decision making, it has been found that the award of yellow cards can influence game outcomes, and the distribution of such cards favours home teams (Anders \& Rotthoff, 2011, 2014).

It is notable that many of the above studies focus on football. The current study examines rugby and there has been less research in this context. An emergent literature does, however, identify the presence of home advantage in the specific context of Rugby Union. Thomas, Reeves, and Bell (2008) and Vaz, Carreras, and Kraak (2012) find evidence of home advantage 
in rugby's Six Nations Championship in Europe based on matches played between 2000 and 2007 and 2005 and 2009 respectively. Pretorius, Litvine, Nevill, and Terblanche (1999) report evidence of home advantage in the Currie Cup, a South African rugby competition, although Pretorius, Pierce, and Litvine (2000) subsequently attribute this to the effects of altitude. Gómez, Pollard, and Pascual (2011) suggest that the high level of home advantage observed in Spanish rugby reflects the continuous, aggressive and intense nature of the sport, particularly with home competitors.

These studies did not focus on officials. In contrast, Page and Page (2010) found evidence of referee bias in Rugby Union's southern hemisphere Super 14 and Rugby League's Euro Super League. However, their study focuses on a rather unique situation where, in both competitions, referees officiated in matches involving teams from their own country playing a team from another country. It is found that shared national identity with the referee increases the likelihood of a win, as well as favourable within-game decisions such as the awarding of penalties and the award of yellow cards. It is also shown that the bias increases when scores are closest between competitors.

Increased monitoring of officials has been made possible in sports by the presence of additional on-field officials or the use technological monitoring. As noted earlier, additional monitoring could have both positive and negative effects on the performance of officials. On the one hand the presence of a peer - physically or remotely - can induce higher performance and effort and reduce the effects of bias. On the other hand, the presence of assistance may result in over-reliance which in turn can induce greater pressure from other sources such as the crowd who become increasingly irritated by what they may perceive as the apparent indecisiveness of the officials.

Empirical studies have tended to focus on the impact of increased capacity to monitor sports matches on player behaviour, however. For example, McCormick and Tollison (1984) in 
the case of North American college basketball find that an increase in the number of officials resulted in a significant reduction in the number of fouls called per game because of asserted greater competence in officiating. However, Heckelman and Yates (2003) find that following an increase in the number of officials in the National Hockey League, there was no reduction in the incidents of foul play, but an increase in the number of incidents of foul play that were observed and sanctioned. Finally, Dawson (2014) finds limited evidence to support the view that the introduction of two additional assistant referees in UEFA Champions League matches over the period 2008/9 to 2011/12 affected the number of fouls called, sanctionable offences observed and attacking play.

A common feature of all the above studies is that they typically refer to on-field officials. Increasingly the use of third-party assistance has been implemented in a number of sports which is directly aimed at monitoring officials' decisions and has begun to attract attention in the academic literature. Hamrick and Rasp (2015) report that the camera monitoring of strike calls in baseball led to a slight increase in the chance that a pitch was called a strike by umpires. Likewise, Shivakumar (2018) analyses the Decision Review System (DRS) in cricket, in which teams can appeal to a third umpire who has access to technological monitoring, up to two times per innings. It is shown that whilst the DRS system does not contribute to home bias, there has been an erosion of the traditional benefit of doubt given to the batsman. Finally, Mills (2017) investigates the impact of the development of technological monitoring of, first, the accuracy of ball-strike calls and, second, new ball-tracking technology, used to feedback accuracy to umpires after games. Improvements in accuracy are identified, with a particular effect on younger officials.

To the best of our knowledge, there have been limited analyses of referee bias in the context of rugby in general and Rugby Union in particular. Moreover, there are no studies on the potential impact of technological monitoring in rugby, although it is not a new phenomenon. In 
2001/02, a television match official was introduced to ERC Rugby to help the on-field referee decide if the ball had been legitimately grounded for a try. The television match official's role was expanded in 2013/14 to include reviews of possible foul play. In what follows, therefore, this paper examines for the first time both the introduction and extension of the television match official in rugby union to determine whether the television match official has influenced the incidence of disciplinary sanctions - in the form of yellow and red card offences - and in the awarding of penalty tries. In particular, the paper investigates the hypothesis of Downward and Jones (2007), and reflecting the theoretical mechanisms previously identified, that the presence of additional monitoring through the television match official could reduce favouritism and therefore bias.

\section{Data and methodology}

The dataset covers matches played in the group stages of the ERC/ERCC between 2000/01 and 2015/16. A small number of missing values associated with attendances and referee experience provides a total sample size of 1,121 matches.

As noted above, several studies of bias in football have focused on decisions on the additional time to be added on at the end of a match which is at the discretion of the referee (Garicano et al., 2005). In top level rugby matches, the referee is not the time-keeper so the scope to favour the home team by playing additional time is limited. Consequently, this paper follows the above literature that analyses the awarding of yellow cards to players for signs of possible referee bias. Yellow cards were introduced to the ERC at the start of the 2000/01 season. ${ }^{2}$ In rugby a player who is shown a yellow card is excluded from the match for a period of 10 minutes and cannot be replaced thus leaving the player's team a player short for that period. The analysis also focuses on the award of red cards. A red card results in a player's permanent expulsion from

\footnotetext{
2 Sendings-off and red cards have been in operation much longer.
} 
the current match. In rugby, moreover, a penalty try may be awarded when the referee believes that foul play prevented a try from being scored. Consequently, the paper also examines if more penalty tries are awarded to the home team.

The data show a higher proportion of yellow and red cards being awarded to the away team. Penalty tries are rare, which is perhaps not surprising as the referee must be certain that a try would probably have been scored in the absence of the infringement. Thus, in the 1,121 ERC pool stage matches in the sample, only 122 penalty tries were awarded, although nearly twice as many were awarded to home teams as to away teams (78 versus 44). Red cards are also rare; 16 red cards were issued to the home team and 27 issued to the away team in the sample ${ }^{3}$

The key feature of this paper is the impact of the television match official on the incidence of yellow and red cards and the awarding of penalty tries. A preliminary analysis of the mean number of incidences (yellow cards, red cards and penalty tries) before and after the introduction of the television match official in 2001/02 and extension of their role in 2013/14 is provided in Table 1. There is a marginal increase in yellow cards awarded to the home team but a larger increase for the away team following the introduction of the television match official (to mitigate against possible trend effects associated with rule changes which could influence home bias, as previously noted, a season-based time trend is included in the conditional estimations detailed below). A further increase is observed for yellow cards awarded to home teams whereas there is a fall for away teams following the extended role of the television match official. Much smaller increases are associated with the awarding of penalty tries when comparing the period before the introduction of the television match official but larger increases following the extended role of the television match official. Finally, reductions in red cards are observed for both home and

\footnotetext{
${ }^{3}$ Full details on the distributions relating to the incidence of yellow and red cards and penalty tries are available from the corresponding author upon request.
} 
away teams following the introduction and extension of the television match official.

Table 1 near here.

In the empirical analysis that follows the dependent variable is constructed to combine both yellow and red cards and penalty tries as well as for these three types of incident separately. Following Dawson et al., (2007) the composite measure weights a red card as double that of a yellow card. For the purpose of this study penalty tries are given the same weight as a yellow card. This is consistent with the view, often reported in the media, that teams concede 7-8 points on average during the period of a yellow card; a penalty try is worth five points and the subsequent conversion, worth 2 additional points, is almost always scored as the kick is taken from in front of the posts (Petty, 2014).

One approach to modelling incidents of yellow card offences is to use count data regression models within a bivariate framework (Dawson et al., 2007). However, it is also possible to model count data using discrete choice methods (Cameron \& Trivedi, 2005) and such methods have previously been adopted by Dawson and Dobson (2010) and Dawson (2012). Given the distribution of disciplinary sanctions, we believe it is both appropriate and sensible to adopt a discrete choice framework. Specifically, we utilise a generalised bivariate ordered response framework for the composite measure and yellow card offences and a generalised bivariate binary response framework for red cards and penalty tries, given their relative infrequency.

The generalised bivariate ordinal / binary regression model is:

$$
\begin{aligned}
& Y_{h}^{*}=\mathbf{X}^{\prime} \beta_{h}+u_{h} \\
& Y_{a}^{*}=\mathbf{X}^{\prime} \beta_{\mathrm{a}}+u_{a}
\end{aligned}
$$

Where $Y^{*}{ }_{h}$ and $Y_{a}{ }^{*}$ are latent variables associated with the home and away team, respectively, $\mathbf{X}^{\prime}$ are row vectors of explanatory variables and $u_{h}$ and $u_{a}$ are unobserved residuals that may be 
stochastically dependent and non-normally distributed. For the various specifications of the dependent variable being estimated, the latent variables are constructed according to the criteria as set out in Table 2 .

Table 2 near here.

A number of important explanatory variables are included in the analysis. Table 3 contains their description and descriptive statistics. To assess the impact of the television match official, dummy variables scored one (and otherwise zero) are included for matches in which a television match official was operational and for matches when the role of the television match official was extended.

Table 3 near here.

Other confounding influences are controlled for as identified in the literature. Differences in team quality may affect the number of offences committed as a weaker team may commit more infringements and therefore be issued with a higher number of sanctionable offences (Madrigal \& James, 1999). To capture relative team quality, the ranking points system which was used to seed the ERC pool draw from 2007/08 onwards is used. Teams received four points for finishing top of their ERC group, three points for second and so on. They received further points depending on how far they progressed in the knock-out stages with a maximum of 11 points for the winning team. Teams participating in a subsidiary competition, the European Challenge Cup, were also awarded ranking points for reaching the knockout stages of that competition. The ERC rankings were determined by the cumulative total ranking points earned by each team over the previous four seasons. In this paper ranking points for each team for each season from the inception of the ERC in 1995/96 onwards were estimated using the ERC ranking points system. Rather than using cumulative ranking points over the previous four years, a weighted-points total for each team over the previous four years with the weights declining with time was estimated. The ranking points for each team for season $t$ is $\Sigma\left(p_{i t-1}+.75 p_{i t-2}+.5 p_{i t-3}\right.$ 
$\left.+.25 \mathrm{p}_{\mathrm{it}-4}\right)$ where $\mathrm{p}_{\mathrm{i}}$ is the number of ranking points. Teams were then ranked into four groups based on the estimate of ranking points for each team. The highest ranked teams were given a ranking of 1 the next ranked teams were ranked 2 and so on. Thus, the model includes a variable which measures the difference in ranking as a measure of differences in team quality where the rankings range from 1 to 4 .

As well as variables relating to the television match official and relative team quality variables relating to match attendance and ground capacity are included. As noted previously, the role of the crowd is a well-established determinant of the social pressure on the match officials and players leading to home advantage.

The nationality of the participating teams and the referee for each match along with the number of matches in the competition in which the referee previously officiated, which is used as a proxy for referee experience, are also included. For example, a more experienced referee might be less susceptible to crowd influence. Dawson (2012), for example, found a reduction in the number of disciplinary sanctions issued with respect to football referees with more experience officiating in European club cup competitions.

Other match-based characteristics that are included as confounding effects relate to the game number of the group stage, if the teams playing are still able to qualify, have qualified or can no longer qualify for the knock-out phase, and whether the contest takes place in the evening are included. Finally, a variable relating to the introduction of the bonus point to see whether the more attacking play this was designed to encourage also increased the number of offences committed.

\section{Results and discussion}

The empirical results presented and discussed reflect analysis based on two main themes derived from the construction of the dependent variable; the composite incident of sanctions and the separate analysis of yellow and red cards, and the awarding of penalty tries. In all cases the 
model estimated error term is assumed to be distributed according to a Clayton copula function. ${ }^{4}$ In all models the null hypothesis of equal coefficients, $H_{0}: \beta_{h}=\beta_{a}$, which is tested on the basis of a Wald test, can be rejected, showing that the models have an overall statistical relevance.

Table 4 reports results for Models 1 and 2 in which a composite measure that combines all three types of offences is considered. In Model 3 attention is restricted to a composite measure of sanction based only on the incidence of yellow and red cards.

Table 4 near here.

Model 1 includes all the explanatory variables other than team nationality and referee nationality. The main findings are that there are positive and statistically significant effects associated with the introduction of the television match official for the away team (but only at the $10 \%$ level of significance). No effect however is found following the extended role of the television match official. There are (at least) two possible interpretations of this. First, and despite initially only adjudicating on the awarding of a try, the television match official acts as monitoring device, implicitly making the on-field referee more vigilant to acts of foul play. Alternatively, it could be that acceptance of aggressive, and strategic behaviour of players has generally increased over time.

Referee appearances, which proxy referee experience, are also an important determinant. It is shown that more experienced referees issue fewer sanctions compared to less experienced officials, a finding that is consistent with Dawson (2012). The effect size is similar across both

${ }^{4}$ Other copula models were also considered (e.g. Gaussian, Frank, Gumbel and Joe) but the Clayton provided the best fit according to the likelihood function. 
home and away teams ${ }^{5}$.

There is also evidence that social pressure, in the form of the crowd, matters. For home teams, fuller stadia result in more sanctions issued to the home team whereas it is the absolute size of the crowd which appears to increase the number of sanctions issued to the away team. Fuller stadia could suggest more balanced crowd influences as suggested by Pollard (1986) and Clarke and Norman (1995) and Downward and Jones (2007).

Relative team quality is also important, affecting the home team negatively (decreasing the number of offences) and the away team positively (increasing the number of offences) as indicated in the literature (Madrigal \& James, 1999). In the case of the away team, this is consistent with the view that weaker teams commit more offences. The negative sign associated with the home team is unexpected and could relate to implicit bias of officials seeking to compensate for lower quality, but the effect is only marginally significant. Finally, the round number of the group stage of the competition is associated with an increase in offences. This makes sense since matches towards the end of the group stage are potentially more important in determining the final group standings and are likely to be more fiercely contested as with playoffs (Longley \& Lacey, 2012).

The main results associated with the television match official and referee experience hold up with the inclusion of team nationality and referee nationality variables being added in Model 2 and the results also show that the size of attendances increases the number of offences by both

\footnotetext{
${ }^{5}$ To mitigate against possible selection effects a series of robustness checks were performed in relation to referee experience. This included robustness checks by restricting the sample to referees to similar levels of experience as well as interacting referee experience with the television match official dummies. These robustness checks (which are available from the corresponding author on request) do not change the main findings reported here.
} 
the home and away team. This could also be linked to the later stages of competition and increased rivalry and fan interest. There is also evidence that the interaction of attendance size and the rank of the team reduce the number of sanctions issued to the home team. In contrast to Model 1 , the relative team quality measure is no longer significant. This is likely to be a result of the correlation between relative team quality and team nationality effects.

When the composite measure is restricted to yellow and red cards (Model 3) similar results to those presented in Model 2 are found, but here the extended role of the television match official is now significant. The season time trend also implies that offences committed have fallen over time, but the effect is only significant for the away team. Given the construction of the dependent variable in this model, the number of penalty tries awarded to the home and away team can be added as additional explanatory variables. As perhaps expected, matches in which a penalty try is awarded to the home team are also associated with higher levels of yellow and red cards issued to the away team. In a similar manner, higher levels of yellow and red cards issued to home teams tend to coincide with penalty tries awarded to away teams.

The second set of the empirical results considers the award of yellow cards, red cards and penalty tries separately, with the results reported in Table 5. The results associated with the consideration of just yellow card offences (Model 4) is in line with the results of the corresponding model that combine yellow and red cards (Model 3). This is to be expected since, as noted earlier, the distribution of yellow cards has much the highest frequency of all offence types considered.

Table 5 near here.

In the case of red cards alone (Model 5) there is evidence that the extended role of the television match official has led to a decrease in the probability of a red card being issued to the home team but no evidence that the probability of a red card being issued changed with the television match official's initial introduction. Here no effect at all for red card offences 
committed by the away team is identified. There is also no evidence to suggest that referee experience matters. Strong evidence is, however, found that red cards often precede or are followed by yellow cards and/or penalty tries especially against away teams. It is in this specification that the strongest effect statistically in relation to home teams already qualified is observed. A significant reduction in sanctions is observed for both the home and away team. In a similar manner, when the away team cannot qualify, there is a similar reduction in the number of offences committed by the home team. Interestingly in circumstances in which the away team has already qualified, increases in offences are observed for both the home team and away team. An increase in the probability of red cards awarded to home teams is also observed.

Finally, in Model 6 attention focuses on penalty tries. In this specification no evidence of a television match official effect is found although there is evidence that more experienced referees are less likely to award penalty tries to the home team and the combination of attendance and rank now has a negative impact on penalty tries awarded to the away team. As in Model 5, similar effects are associated with the perceived intensity of the match (with respect to the home team having already qualified). In a similar manner, penalty tries often follow or are preceded by the award of yellow and red cards. The probability of a penalty try awarded to the home team is positively and statistically significantly related to a yellow or red card issued to the away team and are less likely to be awarded a penalty try when they have a player sent-off. For the away team only matches where one or more yellow cards has been issued to the home team increase the probability of a penalty try being awarded.

\subsection{Implications and future research}

The main finding and the key contribution of the paper is that the presence of additional monitoring through the use of the television match official, both when it was first introduced and when the role was expanded, has had an influence on the issuing of yellow and red cards and in the awarding of penalty tries to the home and away teams. To the extent that the adoption of the 
television match official has increased the number of yellow cards awarded to the away team this implies that home advantage has increased since its introduction. This suggests that there have been unintended consequences associated with its adoption. It appears that referees might have been trying to counter home advantage bias without the television match official. This is evidence of 'game management' in which officials engage in discretionary and perceived desirable application of the laws of the game with referees making judgements based on the context of the game (MacMahon \& Mildenhall, 2012). The above analysis suggests that, in the absence of the television match official, officials informally countered home advantage but then adjusted their behaviour with the additional monitoring. Whether this was conscious or unconscious cannot be established from the data, but clearly merits further investigation.

There are a number of implications of these findings for sport management. The first is that they further demonstrate the usefulness of the Principal-Agent theoretical model to understanding game management in sporting contexts. As identified earlier in the literature, the effects of additional monitoring in a Principal-Agency context are predicted to vary depending on the implementation of the monitoring and the purpose to which it is put. The results in this paper confirm this and suggest that there is not a simple necessary outcome of improved balance in decision making following the adoption of technology, as perhaps suggested by Downward and Jones (2007) and has been found to be the case empirically by Shivakumar (2018).

The second and related implication is that the implementation of additional technological monitoring in sport highlights that the nature of sport is, in general, a context laden activity and needs to be managed as such. Specifically in the context of official decision making adding additional monitoring, as Collins (2010) argues, challenges the ontological authority, of the official, with match outcomes potentially becoming dependent on the form of monitoring of a game. In this sense the nature of the sports product changes. It follows that the potential interrelationships between the competitors and officials has to be considered fully before making 
changes to monitoring mechanisms in order to avoid unintended consequences. As noted earlier, though debated, the impact of yellow cards in rugby can be profound. High profile officials such as Nigel Owens identify that between 7 and 10 points can be conceded during the period of a yellow card (BBC, 2017). At the same time winning margins have been noted to be in the region of 11 points in both the northern and southern hemispheres (Premiership Rugby, 2013; Talking Rugby Union, 2013). It follows that the impact of yellow cards, that is one decision of the official, can be decisive in determining match results.

The third implication is that to reduce the variance of outcomes through bias, the same monitoring approach should be adopted for all matches in a competition. This is particularly important in the context of rugby because currently not all matches have a television match official in some competitions and the same referee may be involved across these matches. Generally, it is clear that the management of officials needs to be adapted to ensure that officials recognise how the television match official may affect their decision making and, of course, mechanisms for reducing this influence need to be established.

A number of implications also arise specifically for the specific management of rugby. Critics have argued that the use of the television match official has added significantly to the duration of rugby matches (The Economist, 2015). In one high profile ERCC match in 2017/18 the television match official review took 6 minutes and 40 seconds before a decision was reached (Thornley, 2018) while World Rugby subsequently announced that the television match official had erred by failing to awarda try in the 2018 Six Nations Championship match between England and Wales (Rees, 2018). Issues have also been raised about control over replays with suggestions that broadcasters may not provide images to television match officials that might prove unfavourable to the home team (Thornley, 2018). If correct this could also partly explain the findings that the television match official has increased the number of yellow cards awarded to away teams. If this is the case this clearly needs correction. However, this would increase the 
cost of the television match official to the sport and independent control over images from the broadcasters would be needed. More generally, these discussions recognise that it is not clear to stakeholders that the role of the television match official is neutral on decision making and therefore necessarily advantageous to the sport.

Consequently, further adjustments to the role of the television match official are taking place. Super Rugby amended its television match official rules in 2017 limiting television match official interventions to cases involving blatant errors by the on-field referee (Radio New Zealand, 2017). Finally, The Economist (2015) argued that television match officials should be located away from the ground, as Downward and Jones (2007) suggested, rather than in outside broadcast vehicles in the stadium, where crowd influences may persist. Further scrutiny of the role and impact of television match officials is thus important by governing bodies to remove the risks of outcomes being potentially determined through biases.

A number of avenues for future research are also raised by the paper and could be addressed if other data permit their investigation. Clearly, underlying team performance and strategy is the possibility that teams do not always field their strongest sides whilst playing away from home, or they lose motivation, which has been noted in rugby (Julian, 2017; Ray, 2018). It follows that future research could attempt to match teams and their squads as closely as possible in seeking to control for such confounding effects, that simple controls for previous form of teams do not capture. A further issue is that yellow cards, or other sanction, can have different effects at different times of the game. To lose a player for the majority of a game to a red card is likely to condemn a side to certain defeat. In contrast for a team to lose a player to a yellow card, with two minutes to play may not affect the result, assuming that this is not in a situation in which the yellow card went to a defending side under duress close to the try line and the scores are very close. Timing has been shown to matter in official sanction in football (Buraimo et al., 2010).

\subsection{Conclusion}


Whilst a lack of bias in sporting competition has always been viewed as desirable in sport, it is well known that home advantage applies to many sports. Through the influence of crowds, match officials are identified as a key source of the mediation of home bias as crowds, amongst other factors such as nationality, familiarity with teams and players can influence the subjective judgement and potential preferences of officials. In the context of a Principal-Agency Problem, in which officials are imperfectly monitored by sports organisers, this has prompted the use of the television match official to help to remove subjective judgement. Based on an analysis of the award of sanctionable offences in matches played in the group stages of the European Rugby Cup (ERC) and European Rugby Champions Cup (ERCC) over 15 seasons from 2000/01 to $2015 / 16$, the key finding of this paper is that the use of the television match official has increased the number of yellow cards awarded to away teams, increasing home bias and suggesting that referees may have been consciously or unconsciously seeking to avoid contributing to home bias before the introduction of the television match official. Recognising that such an adjustment takes place according to the circumstances of the match is important information for the management and planning of the monitoring of sports officials. Only through a clearer understanding of how third-party scrutiny influences decisions can officials receive the relevant training that they deserve to cope with this added influence on their behaviour. 


\section{References}

Anders, A., \& Rotthoff, K. W. (2011). Yellow cards: Do they matter? Journal of Quantitative Analysis in Sports, 7(1), 1-12. .https://doi.org/10.2202/1559-0410.1286

Anders, A., \& Rotthoff, K. W. (2014). Is home-field advantage driven by the fans? Evidence from across the ocean. Applied Economics Letters, 21(16), 1165-1168. https://doi.org/10.1080/13504851.2014.914139

BBC. (2017). Nigel Owens: Top rugby referee backs football sin-bin plan - BBC Sport. Retrieved November 20, 2018, from https://www.bbc.co.uk/sport/football/39806745

Boyko, R. H., Boyko, A. R., \& Boyko, M. G. (2007). Referee bias contributes to home advantage in English Premiership football. Journal of Sports Sciences, 25(11), 11851194. https://doi.org/10.1080/02640410601038576

Bryson, A., Buraimo, B., \& Simmons, R. (2011). Do salaries improve worker performance? Labour Economics, 18(4), 424-433. https://doi.org/10.1016/J.LABECO.2010.12.005

Buraimo, B., Forrest, D., \& Simmons, R. (2010). The 12th man?: Refereeing bias in English and German soccer. Journal of the Royal Statistical Society: Series A (Statistics in Society), 173(2), 431-449. https://doi.org/10.1111/j.1467-985X.2009.00604.x

Buraimo, B., Simmons, R., \& Maciaszczyk, M. (2012). Favoritism and referee bias in european soccer: Evidence from the Spanish league and the UEFA Champions League. Contemporary Economic Policy, 30(3), 329-343.

https://doi.org/10.1111/j.1465-7287.2011.00295.x

Cameron, C. A., \& Trivedi, P. K. (2005). Microeconometrics: Methods and applications. Cambridge, UK: Cambridge University Press.

Carron, A. V, Loughhead, T. M., \& Bray, S. R. (2005). The home advantage in sport competitions: Courneya and Carron's (1992) conceptual framework a decade later. 
Journal of Sports Sciences, 23(4), 395-407. ttps://doi.org/10.1080/02640410400021542

Clarke, S. R., \& Norman, J. M. (1995). Home ground advantage of individual clubs in English soccer. The Statistician, 44(4), 509. https://doi.org/10.2307/2348899

Collins, H. (2010). The philosophy of umpiring and the introduction of decision-aid technology. Journal of the Philosophy of Sport, 37(2), 135-146. https://doi.org/10.1080/00948705.2010.9714772

Council of Europe. (2010). Recommendation CM/Rec(2010)9 of the Committee of Ministers to member states on the revised Code of Sports Ethics. (Adopted by the Committee of Ministers on 16 June 2010 at the $1088^{\text {th }}$ Meeting of the Ministers' Deputies). Retrieved November 162018 from

https://search.coe.int/cm/Pages/result_details.aspx?ObjectID=09000016805cecaa

Courneya, K. S., \& Carron, A. V. (1992). The home advantage in sport competitions: A literature review. Journal of Sport and Exercise Psychology, 14(1), 13-27. https://doi.org/10.1123/jsep.14.1.13

Dawson, P. (2012). Experience, social pressure and performance: The case of soccer officials. Applied Economics Letters, 19(9), 883-886.

https://doi.org/10.1080/13504851.2011.607118

Dawson, P. (2014). Refereeing and infringement of the rules in P. Sloane \& J. Goddard (Eds.), Handbook on the economics of football (pp. 401-418). Cheltenham, UK: Edward Elgar Publishing.

Dawson, P.,\& Dobson, S. (2010). The influence of social pressure and nationality on individual decisions: Evidence from the behaviour of referees. Journal of Economic Psychology, 31(2), 181-191. https://doi.org/10.1016/J.JOEP.2009.06.001

Dawson, P., Dobson, S., Goddard, J., \& Wilson, J. (2007). Are football referees really biased 
and inconsistent?: Evidence on the incidence of disciplinary sanction in the English Premier League. Journal of the Royal Statistical Society: Series A (Statistics in Society), 170(1), 231-250. https://doi.org/10.1111/j.1467-985X.2006.00451.x

Dohmen, T., \& Sauermann, J. (2016). Referee bias. Journal of Economic Surveys, 30(4), 679695. https://doi.org/10.1111/joes. 12106

Downward, P., Dawson, A., \& Dejonghe, T. (2009). Sports economics: Theory, evidence and policy. https://doi.org/10.4324/9780080942087

Downward, P., \& Jones, M. (2007). Effects of crowd size on referee decisions: Analysis of the FA Cup. Journal of Sports Sciences, 25(14), 1541-1545.

https://doi.org/10.1080/02640410701275193

Frey, B. S. (1993). Does monitoring increase work effort? The rivalry with trust and loyalty. Economic Inquiry, 31(4), 663-670. https://doi.org/10.1111/j.1465-7295.1993.tb00897.x

Garicano, L., Palacios-Huerta, I., \& Prendergast, C. (2005). Favoritism under social pressure. Review of Economics and Statistics, 87(2), 208-216.

https://doi.org/10.1162/0034653053970267

Garside, L., Grout, P. A., \& Zalewska, A. (2013). Does experience make you 'tougher'? Evidence from competition law. The Economic Journal, 123(568), 474-490. https://doi.org/10.1111/j.1468-0297.2012.02560.x

Gómez, M. A., Pollard, R., \& Luis-Pascual, J.-C. (2011). Comparison of the home advantage in nine different professional team sports in Spain. Perceptual and Motor Skills, 113(1), 150-156. https://doi.org/10.2466/05.PMS.113.4.150-156

Hamrick, J., \& Rasp, J. (2015). The connection between race and called strikes and balls . Journal of Sports Economics, 16(7), 714-734.

https://doi.org/10.1177/1527002513509817 
Heckelman, J.C., \& Yates, A.J., (2003). And a hockey game broke out: crime and punishment in the NHL. Economic Inquiry, 41(4), 705-712. https://doi. org/10.1093/ei/cbg038

Hlasny, V., \& Kolaric, S. (2017). Catch me if you can. Journal of Sports Economics, 18(6), 560-591. https://doi.org/10.1177/1527002515588955

Jones, M. V., Bray, S. R., \& Bolton, L. (2001). Do cricket umpires favour the home team? Officiating bias in English club cricket. Perceptual and Motor Skills, 93(2), 359-362. https://doi.org/10.2466/pms.2001.93.2.359

Julian, B. (2017). Why is it so difficult to win away from home in rugby union? The Daily Telegraph. Retrieved November 20, 2018 from https:/www.telegraph.co.uk/rugbyunion/2017/01/28/difficult-win-away-home-rugby-union/

Kendall, G., \& Lenten, L.J., (2017). When sports rules go awry. European Journal of Operational Research, 257(2), 377-394. https://doi.org/10.1016/j.ejor. 2016.06 .050

Laffont, J.-J., \& Martimort, D. (2002). The theory of incentives : The principal-agent model. Princeton N.J.: Princeton University Press.

Lazear, E. P. (1995). Personnel economics. Cambridge, Mass: MIT Press.

Longley, N., \& Lacey, N. J. (2012). The "second" season. Journal of Sports Economics, 13(5), 471-493. https://doi.org/10.1177/1527002511410932

MacMahon, C., \& Mildenhall, B. (2012). A practical perspective on decision making influences in sports officiating. InternationalJournal of Sports Science \& Coaching, 7(1), 153-165. https://doi.org/10.1260/1747-9541.7.1.153

Madrigal, R., \& James, J. (1999). Team quality and the home advantage. Journal of Sport Behavior, 22(3), 381-399.

Mascarenhas, D. R. D., Collins, D., \& Mortimer, P. (2005). Elite refereeing performance: Developing a model for sport science support. The Sport Psychologist, 19(4), 364-379. 
https://doi.org/10.1123/tsp.19.4.364

McCormick, R. E., \& Tollison, R. D. (1984). Crime on the court. Journal of PoliticalEconomy, 92(2), 223-235. https://doi.org/10.1086/261221

Mills, B. M. (2017). Technological innovations in monitoring and evaluation: Evidence of performance impacts among Major League Baseball umpires. Labour Economics, 46 (1), 189-199. https://doi.org/10.1016/j. labeco.2016.10.004

Nevill, A., Balmer, N., \& Williams, M. A. (2002). The influence of crowd noise and experience upon refereeing decisions in football. Psychology of Sport and Exercise, 3(4), 261-272. https://doi.org/10.1016/S1469-0292(01)00033-4

Nevill, A. M., Hemingway, A., Greaves, R., Dallaway, A., \& Devonport, T. J. (2017). Inconsistency of decision-making, the Achilles heel of referees. Journal of Sports Sciences, 35(22), 2257-2261. https://doi.org/10.1080/02640414.2016.1265143

Nevill, A. M., \& Holder, R. L. (1999). Home advantage in sport. Sports Medicine,28(4), 221236. https://doi.org/10.2165/00007256-199928040-00001

Page, L., \& Page, K. (2010). Evidence of referees' national favouritism in rugby. NCER Working Paper Series, 62. Reterieved March 1, 2019 from https://econpapers.repec.org/paper/qutauncer/2010_5f09.htm

Parsons, C. A., Sulaeman, J., Yates, M. C., \& Hamermesh, D. S. (2011). Strike three: discrimination, incentives, and evaluation. American Economic Review, 101(4), 14101435. https://doi.org/10.1257/aer.101.4.1410

Peeters, T., \& Szymanski, S. (2014). Financial fair play in European football. Economic Policy, 29(78), 343-390. https://doi. org/10.111 1/1468-0327.12031

Petty, R. (2014, September 23). Are yellow cards in rugby really that bad? Rugby World. Retrieved November 20, 2018 from 
https:/www.rugbyworld.com/tournaments/european-champions-cup/stats-yellow-cardsreally-bad-39058

Pollard, R. (1986). Home advantage in soccer: A retrospective analysis. Journal of Sports Sciences, 4(3), 237-248. https://doi.org/10.1080/02640418608732122

Pollard, R. (2008). Home advantage in football: A current review of an unsolved puzzle. The Open Sports Sciences Journal, 1(1), 12-14.

https://doi.org/10.2174/1875399X00801010012

Premiership Rugby. (2013). Television match officials in all Aviva Premiership Rugby matches, Premiership Rugby. Retrieved November 20, 2018, from https://www.premiershiprugby.com/news/television-match-officials-in-all-avivapremiership-rugby-matches/

Prendergast, C., \& Topel, R. (1996). Favouritism in organizations. Journal of Political Economy, 104(5), 958-978. http://dx.doi.org/10.1086/262048

Pretorius, B., Litvine, I. N., Nevill, A. M., \& Terblanche, L. (1999). An analysis and estimation of home and away game performance of South African rugby teams: Is a home field advantage present? South African Journal of Research in Sport, Physical Education and Recreation, 21, 69-80.

Pretorius, B., Pierce, M. W., \& Litvine, I. N. (2000). The possible effect of climate and altitude on home advantage and game performance in South African rugby teams, South African Journal of Research in Sport, Physical Education and Recreation, 22, 37-48.

Radio New Zealand (2017). Super rugby serves up TMO changes | RNZ News. Retrieved November 20, 2018, from https:/www.radionz.co.nz/news/sport/324738/super-rugbyserves-up-tmo-changes

Rains, P. (1984). The Production of fairness: Officiating in the National Hockey League. 
Sociology of Sport Journal, 1(2), 150-162. https://doi.org/10.1123/ssj.1.2.150

Ray, C. (2018). Springboks to box clever in Rugby Championship. Sunday Times. Retrieved November 20, 2018 from https:/www.timeslive.co.za/sport/rugby/2018-08-07springboks-to-box-c lever-in-rugby-championship/

Rees, P. (2018). Precedent is everything in the murky confused world of TMO decisions. The Guardian. Retrieved Novermber 20, 2018 from

https://www.theguardian.com/sport/2018/feb/15/tmo-decis ion-wales-england-precedentsix-nations

Reilly, B., \& Witt, R. (2013). Red cards, referee home bias and social pressure: Evidence from English Premiership soccer. Applied Economics Letters, 20(7), 710-714. https://doi.org/10.1080/13504851.2012.734591

Renson, R. (2009). Fair play: Its origins and meanings in sport and society. Kinesiology, 1, 518.

Rodenberg, R.M., \& Lim, C.H. (2009). Payback calls: a starting point for measuring basketball referee bias and impact on team performance. European Sport Management Quarterly, 9(4), 375-387.

Shivakumar, R. (2018). What technology says about decision-making. Journal of Sports Economics, 19(3), 315-331. https://doi.org/10.1177/1527002516657218

Sutter, M., \& Kocher, M. G. (2004). Favoritism of agents-the case of referees' home bias. Journal of Economic Psychology, 25(4), 461-469. https://doi.org/10.1016/S0167-4870(03)00013-8

Talking Rugby Union. (2013). Super Rugby 2013 - The most popular winning margins. Retrieved November 20, 2018, from http://www.talkingrugbyunion.co.uk/super-rugby2013-the-most-popular-winning-margins/9806.htm 
Taylor, E. S., \& Tyler, J. H. (2012). The effect of evaluation on teacherperformance. American Economic Review, 102(7), 3628-3651. https://doi.org/10.1257/aer.102.7.3628

The Economist. (2015). Bad reviews - instant replay in rugby. The Economist. Retrieved November 20, 2018 from https:/www.economist.com/game-the ory/2015/10/23/badreviews

Thomas, S.; Reeves, C., \& Bell, A., (2008). Home advantage in the Six Nations Rugby Union tournament. Perceptual and Motor Skills, 106(1), 113-116 https://doi.org/10.2466/pms.

Thornley, G. (2018, April 7). Results have vindicated increased use of TMOs, Irish Times.

Retrieved November 20, 2018 from https://www.irishtimes.com/sport/rugby/gerry-thornleyresults-have-vindicated-increased-use-of-tmos- 1.3453185

Trandel, G., \& Maxcy, J. (2011). Adjusting winning-percentage standard deviations and a measure of competitive balance for home advantage. Journal of Quantitative Analysis in Sports. https://doi.org/10.2202/1559-0410.1297

Unkelbach, C., \& Memmert, D. (2010). Crowd noise as a cue in referee decisions contributes to the home advantage. Journal of Sport and Exercise Psychology, 32(4), 483-498. https://doi.org/10.1123/jsep.32.4.483

Vaz, L., Carreras, D. \& Kraak, W. (2012). Analysis of the effect of alternating home and away field advantage during the Six Nations Rugby Championship. International Journal of Performance Analysis in Sport, 12(3), 594-608.

https://doi.org/10.1080/24748668.2012.11868621

Webb, T. (2017). Elite soccer referees. Abingdon-on-Thames, UK: Routledge. https://doi.org/10.4324/9781315656809

Wright, M., (2014). OR analysis of sporting rules-a survey. European Journal of Operational Research,232(1), 1-8. https://doi.org/10.1016/j.ejor.2013.03.043 
Table 1

Mean Number of Yellow and Red Cards and Penalty Tries before and after the introduction of TMO and extended role of TMO

TMO TMO Ext

\begin{tabular}{llll} 
Offence & Before & \multicolumn{1}{l}{ After $^{\mathrm{a}}$} \\
Yellow card: Home & $0.389[0.075]$ & $0.408[0.021]$ & $0.438[0.051]$ \\
Yellow Card: Away & $0.514[0.093]$ & $0.659[0.027]$ & $0.646[0.054]$ \\
Red Card: Home & $0.014[0.014]$ & $0.015[0.004]$ & $0.010[0.007]$ \\
Red Card: Away & $0.028[0.020]$ & $0.025[0.005]$ & $0.021[0.010]$ \\
Penalty Try: Home & $0.056[0.027]$ & $0.062[0.009]$ & $0.109[0.028]$ \\
Penalty Try: Away & $0.014[0.014]$ & $0.037[0.007]$ & $0.057[0.017]$ \\
\hline
\end{tabular}

Notes. Standard errors in parentheses.

a Period after the introduction of the TMO but before the extended role of the TMO.

Table 2

Construction of the Latent Dependent Variable

\begin{tabular}{llll}
\hline \multicolumn{2}{l}{ Composite Measures and Yellow Cards } & & \multicolumn{2}{l}{ Red Cards and Penalty Tries } \\
\hline$Y_{\mathrm{h}}$ & $\mathrm{Ya}_{\mathrm{a}}$ & 0 if $Y_{h}^{*}=0$ & 0 if $Y_{a}^{*}=0$ \\
\hline 0 if $Y_{h}^{*}=0$ & 0 if $Y_{a}^{*}=0$ & 1 if $Y_{h}^{*} \geq 1$ & 1 if $Y_{a}^{*} \geq 1$ \\
1 if $Y_{h}^{*}=1$ & 1 if $Y_{a}^{*}=1$ & & \\
2 if $Y_{h}^{*}=2$ & 2 if $Y_{a}^{*}=2$ & \\
3 if $Y_{h}^{*} \geq 3$ & 3 if $Y_{a}^{*} \geq 3$ & & \\
\hline
\end{tabular}


Table 3

Variable Descriptions

\begin{tabular}{|c|c|c|}
\hline Variable & Definition & Mean (sd) \\
\hline TMOTRY & $\begin{array}{l}\text { Introduction of television match official(TMO) } \\
(1=\text { yes; } 0=\text { no })\end{array}$ & $0.936(0.245$ \\
\hline TMOEXT & $\begin{array}{l}\text { Extended role of the TMO applies to the match } \\
(1=\text { yes; } 0=\text { no })\end{array}$ & $0.171(0.377)$ \\
\hline REFAPPS & $\begin{array}{l}\text { Number of matches in the competition in which } \\
\text { the referee previously officiated } \\
\text { (prior to the current match). }\end{array}$ & $17.26(15.135)$ \\
\hline BONUSPT & $\begin{array}{l}\text { If team scored a "bonus point" (scoring } 4 \text { or } \\
\text { more tries or losing by } 7 \text { points or less }) \\
(1=\text { yes; } 0=\text { no })\end{array}$ & $0.808(0.393)$ \\
\hline $\mathrm{ECC}$ & $\begin{array}{l}\text { The ERC was replaced by the ERCC } \\
(1=\text { yes; } 0=\text { no })\end{array}$ & $0.107(0.309)$ \\
\hline CAPREACHED & $\begin{array}{l}\text { The match sold out the stadium } \\
(1=\text { yes; } 0=\text { no })\end{array}$ & $0.103(0.304)$ \\
\hline ATT & Match attendance & $10,301.25(7,029.54)$ \\
\hline RANK_DIFF & $\begin{array}{l}\text { The difference in ranking points (home team } \\
\text { ranking points minus aw ay team ranking points) }\end{array}$ & $0.002(1.713)$ \\
\hline $\begin{array}{l}\text { ATT* } \\
\text { RANK_DIFF }\end{array}$ & $\begin{array}{l}\text { Interaction of attendance and rank } \\
\text { difference }\end{array}$ & $3,147.74(20,165.77)$ \\
\hline CHAMP & $\begin{array}{l}\text { The team won the ERC or the ERCC in the } \\
\text { previous season }(1=\text { yes; } 0=\text { no })\end{array}$ & $0.207(0.444)$ \\
\hline CANNOTQH & $\begin{array}{l}\text { The home team can no longer qualify for the } \\
\text { knockout stage }(1=\text { yes; } 0=\text { no })\end{array}$ & $0.118(0.322)$ \\
\hline QH & $\begin{array}{l}\text { The home team has already qualified for the } \\
\text { knockout stage }(1=\text { yes; } 0=\text { no })\end{array}$ & $0.010(0.099)$ \\
\hline CANNOTQA & $\begin{array}{l}\text { The away team can no longer qualify for the } \\
\text { knockout stage }(1=\text { yes; } 0=\text { no })\end{array}$ & $0.108(0.310)$ \\
\hline QA & $\begin{array}{l}\text { The away team has already qualified for the } \\
\text { knockout stage }(1=\text { yes; } 0=\text { no })\end{array}$ & $0.017(0.129)$ \\
\hline EVENING & $\begin{array}{l}\text { The match kicked-off after } 5 \mathrm{pm} \\
(1=\text { yes; } 0=\text { no })\end{array}$ & $0.383(0.486)$ \\
\hline ROUND & $\begin{array}{l}\text { Time trend denoting the game number within } \\
\text { the group stage of the competition. }\end{array}$ & $3.500(1.708)$ \\
\hline
\end{tabular}


Table 4

Incidents of Yellow Cards, Red Cards and Penalty Tries - Composite Measures

\begin{tabular}{|c|c|c|c|c|c|c|}
\hline \multirow[b]{2}{*}{ Variable } & \multicolumn{2}{|c|}{$\begin{array}{l}\text { Model 1: } \\
\text { Yellow cards, red cards \& penalty tries }\end{array}$} & \multicolumn{2}{|c|}{$\begin{array}{c}\text { Model 2: } \\
\text { Yellow cards, red cards \& penalty tries }\end{array}$} & \multicolumn{2}{|c|}{$\begin{array}{c}\text { Model 3: } \\
\text { Yellow cards \& red cards }\end{array}$} \\
\hline & Home Team & Away Team & Home Team & Away Team & Home Team & Away Team \\
\hline TMOTRY & $0.295(0.187)$ & $0.347 *(0.200)$ & $0.308(0.202)$ & $0.355 *(0.199)$ & $0.276(0.201)$ & $0.396 * *(0.185)$ \\
\hline TMOEXT & $0.0169(0.174)$ & $0.243(0.150)$ & $0.0457(0.184)$ & $0.244 *(0.145)$ & $0.0980(0.185)$ & $0.305^{* *}(0.119)$ \\
\hline SEASON & $-0.0051(0.016)$ & $-0.0213(0.016)$ & $-0.0096(0.015)$ & $-0.0244(0.016)$ & $-0.022(0.016)$ & $-0.036 * *(0.014)$ \\
\hline REFAPPS & $-0.009 * * *(0.003)$ & $-0.009 * * *(0.002)$ & $-0.009 * *(0.004)$ & $-0.006 * * *(0.002)$ & $-0.009 * * *(0.004)$ & $-0.005 *(0.003)$ \\
\hline BONUSPT & $-0.110(0.154)$ & $0.0913(0.114)$ & $-0.103(0.157)$ & $0.122(0.120)$ & $-0.018(0.159)$ & $0.164(0.110)$ \\
\hline $\mathrm{ECC}$ & $0.258(0.189)$ & $-0.004(0.165)$ & $0.200(0.184)$ & $-0.0192(0.176)$ & $0.186(0.186)$ & $-0.127(0.185)$ \\
\hline CAPREACHED & $0.204 * * *(0.077)$ & $0.0153(0.169)$ & $0.210^{* *}(0.087)$ & $-0.0204(0.155)$ & $0.179 * *(0.080)$ & $-0.018(0.147)$ \\
\hline ATT & $\begin{array}{l}0.0000081 \\
0.0000069\end{array}$ & $\begin{array}{l}0.0000113^{5 * * *} \\
(0.00000392)\end{array}$ & $\begin{array}{l}0.0000116^{* *} \\
(0.00000578)\end{array}$ & $\begin{array}{l}0.0000118^{* *} \\
(0.00000469)\end{array}$ & $\begin{array}{l}0.0000137 * * \\
(0.00000584)\end{array}$ & $\begin{array}{l}0.00000953^{*} \\
(0.00000546)\end{array}$ \\
\hline RANK_DIFF & $-0.0791 *(0.043)$ & $0.093 * * *(0.035)$ & $-0.0038(0.039)$ & $0.0394(0.051)$ & $-0.006(0.04)$ & $0.045(0.051)$ \\
\hline ATT*RANK_DIFF & $\begin{array}{l}-0.00000255 \\
(0.00000362)\end{array}$ & $\begin{array}{l}-0.00000363 \\
(0.00000283)\end{array}$ & $\begin{array}{l}-0.00000725^{* *} \\
(0.00000352)\end{array}$ & $\begin{array}{l}-0.00000180 \\
(0.00000312)\end{array}$ & $\begin{array}{l}-0.00000598^{*} \\
(0.00000359)\end{array}$ & $\begin{array}{l}-0.00000143 \\
(0.00000315)\end{array}$ \\
\hline CHAMP & $-0.134(0.107)$ & $0.072(0.120)$ & $-0.097(0.109)$ & $-0.015(0.120)$ & $-0.087(0.109)$ & $-0.012(0.127)$ \\
\hline CANNOTQH & $-0.0527(0.092)$ & $-0.299 * * *(0.109)$ & $-0.0696(0.101)$ & $-0.283^{* *}(0.118)$ & $-0.071(0.111)$ & $-0.258 * *(0.115)$ \\
\hline QH & $-0.316(0.353)$ & $-0.607(0.399)$ & $-0.271(0.357)$ & $-0.727 *(0.399)$ & $-0.299(0.306)$ & $-0.69(0.406)$ \\
\hline CANNOTQA & $-0.0096(0.124)$ & $0.005(0.113)$ & $0.041(0.130)$ & $0.066(0.117)$ & $0.140(0.134)$ & $0.054(0.124)$ \\
\hline QA & $0.264(0.257)$ & $0.408(0.317)$ & $0.273(0.242)$ & $0.402(0.306)$ & $0.288(0.221)$ & $0.169(0.271)$ \\
\hline EVENING & $0.0148(0.086)$ & $0.0087(0.057)$ & $0.080(0.088)$ & $-0.069(0.070)$ & $0.112(0.095)$ & $-0.092(0.067)$ \\
\hline ROUND & $0.046 * *(0.020)$ & $0.091 * * *(0.022)$ & $0.043 * *(0.020)$ & $0.088 * * *(0.023)$ & $0.037(0.023)$ & $0.064 * * *(0.021)$ \\
\hline РТНОМЕ & & & & & $-0.103(0.101)$ & $0.418 * * *(0.109)$ \\
\hline PTAWAY & & & & & $0.548 * * *(0.181)$ & $0.174(0.122)$ \\
\hline FIXED EFFECTS & \multicolumn{2}{|c|}{ No } & \multicolumn{2}{|c|}{ Yes } & \multicolumn{2}{|c|}{ Yes } \\
\hline THETA & \multicolumn{2}{|c|}{$0.502 * * *(0.118)$} & \multicolumn{2}{|c|}{$0.483 * * *(0.116)$} & \multicolumn{2}{|c|}{$0.459 * * *(0.114)$} \\
\hline $\begin{array}{l}\text { EQUALITY OF } \\
\text { COEFFICIENTS }\end{array}$ & \multicolumn{2}{|c|}{$\chi^{2}(d f=17)=101.162$} & \multicolumn{2}{|c|}{$\chi^{2}(\mathrm{~d} f=32)=766.292$} & \multicolumn{2}{|c|}{$\chi^{2}(\mathrm{df}=34)=549.127$} \\
\hline
\end{tabular}

Notes. $\mathrm{n}=1,121$. Coefficients from bivariate ordered response frameworks. Figures in brackets are robust standard

errors clustered by (home) team. ${ }^{* * *} \mathrm{p}<0.01, * * \mathrm{p}<0.05,{ }^{*} \mathrm{p}<0.1$ 
Table 5

Incidents of Yellow Cards, Red Cards and Penalty Tries - Separate Treatment

\begin{tabular}{|c|c|c|c|c|c|c|}
\hline \multirow[b]{2}{*}{ Variable } & \multicolumn{2}{|c|}{ Model 4: Yellow Cards } & \multicolumn{2}{|c|}{ Model 5: Red Cards } & \multicolumn{2}{|c|}{ Model 6: Penalty Tries } \\
\hline & Home Team & Away Team & Home Team & Away Team & Home Team & Away Team \\
\hline TMOTRY & $0.213(0.190)$ & $0.419 * *(0.184)$ & $0.162(0.435)$ & $-0.057(0.390)$ & $0.007(0.408)$ & $0.394(0.456)$ \\
\hline TMOEXT & $0.159(0.184)$ & $0.324 * * *(0.110)$ & $-5.308 * * *(0.746)$ & $-0.261(0.385)$ & $-0.188(0.371)$ & $-0.322(0.421)$ \\
\hline SEASON & $\begin{array}{l}-0.023 \\
(0.016)\end{array}$ & $-0.040 * * *(0.015)$ & $0.032(0.041)$ & $0.019(0.042)$ & $0.043(0.030)$ & $0.075 * *(0.037)$ \\
\hline REFAPPS & $\begin{array}{l}-0.009 * * \\
(0.004)\end{array}$ & $-0.005 * *(0.002)$ & $-0.004(0.01)$ & $0.008(0.006)$ & $-0.014 * *(0.007)$ & $0.001(0.006)$ \\
\hline BONUSPT & $0.032(0.164)$ & $0.213 * *(0.101)$ & $-0.354(0.366)$ & $-0.293(0.308)$ & $-0.196(0.256)$ & $-0.675 * * *(0.255)$ \\
\hline $\mathrm{ECC}$ & $0.153(0.190)$ & $-0.079(0.180)$ & $5.007 * * *(0.743)$ & $-0.216(0.477)$ & $0.408(0.309)$ & $0.302(0.426)$ \\
\hline CAPREACHED & $\begin{array}{l}0.153 * * \\
(0.075)\end{array}$ & $-0.007(0.151)$ & $0.614 * *(0.257)$ & $-0.170(0.174)$ & $0.015(0.223)$ & $0.379(0.340)$ \\
\hline ATT & $\begin{array}{l}0.0000115 \\
(0.00000536)\end{array}$ & $\begin{array}{l}0.00000977 * \\
(0.00000548)\end{array}$ & $\begin{array}{l}-0.000000303 \\
(0.0000215)\end{array}$ & $\begin{array}{l}-0.00000905 \\
(0.0000159)\end{array}$ & $\begin{array}{l}0.0000146 \\
(0.00000931)\end{array}$ & $\begin{array}{l}-0.0000214 \\
(0.00000242)\end{array}$ \\
\hline RANK_DIFF & $\begin{array}{l}-0.035 \\
(0.040)\end{array}$ & $0.061(0.051)$ & $0.266^{*}(0.161)$ & $-0.055(0.096)$ & $-0.024(0.072)$ & $0.087(0.108)$ \\
\hline ATT*RANK_DIFF & $\begin{array}{l}-0.00000356 \\
(0.00000303)\end{array}$ & $\begin{array}{l}-0.00000280 \\
(0.00000354)\end{array}$ & $\begin{array}{l}-0.0000287 \\
(0.0000133)\end{array}$ & $\begin{array}{l}0.00000857 \\
(0.00000638)\end{array}$ & $\begin{array}{l}-0.00000178 \\
(0.00000435)\end{array}$ & $\begin{array}{l}-0.0000212 \\
(0.00000797)\end{array}$ \\
\hline CHAMP & $\begin{array}{l}-0.085 \\
(0.111)\end{array}$ & $-0.022(0.127)$ & $0.295(0.345)$ & $0.108(0.218)$ & $-0.122(0.148)$ & $0.080(0.212)$ \\
\hline CANNOTQH & $\begin{array}{l}-0.056 \\
(0.114)\end{array}$ & $-0.231 *(0.119)$ & $-0.177(0.555)$ & $-0.274(0.424)$ & $-0.186(0.192)$ & $-0.038(0.250)$ \\
\hline $\mathrm{QH}$ & $0.170(0.233)$ & $0.044(0.267)$ & $-4.383 * * *(0.527)$ & $-4.314 * * *(0.252)$ & $-4.819 * * *(0.317)$ & $-3.774 * * *(0.295)$ \\
\hline CANNOTQA & $0.208(0.140)$ & $0.091(0.125)$ & $-4.765 * * *(0.661)$ & $-0.405(0.490)$ & $0.184(0.170)$ & $-5.154 * * *(0.248)$ \\
\hline QA & $0.170(0.233)$ & $0.044(0.267)$ & $1.257 * *(0.526)$ & $0.918 *(0.510)$ & $0.550(0.392)$ & $-0.265(0.442)$ \\
\hline EVENING & $0.115(0.089)$ & $-0.125 *(0.067)$ & $-0.075(0.277)$ & $0.181(0.168)$ & $0.023(0.144)$ & $-0.226(0.181)$ \\
\hline ROUND & $\begin{array}{l}0.039 * \\
(0.022)\end{array}$ & $0.073 * * *(0.019)$ & $-0.026(0.045)$ & $-0.078(0.058)$ & $0.126 * *(0.060)$ & $0.110 *(0.059)$ \\
\hline YCHOME & & & $-0.022(0.111)$ & $0.221(0.166)$ & $-0.045(0.078)$ & $0.367 * * *(0.098)$ \\
\hline YCAWAY & & & $0.015(0.113)$ & $0.170 * *(0.077)$ & $0.234 * * *(0.063)$ & $0.113(0.081)$ \\
\hline RCHOME & $\begin{array}{l}-0.042 \\
(0.226)\end{array}$ & $0.206(0.256)$ & & & $-4.557 * * *(0.344)$ & $-0.094(0.415)$ \\
\hline RCAWAY & $0.463(0.313)$ & $0.395 * *(0.167)$ & & & $0.774 * *(0.353)$ & $-0.112(0.500)$ \\
\hline PTHOME & $\begin{array}{l}-0.077 \\
(0.107)\end{array}$ & $0.357 * * *(0.119)$ & $-5.131 * * *(0.689)$ & $0.597 * *(0.245)$ & & \\
\hline PTAWAY & $\begin{array}{l}0.614 * * * \\
(0.184)\end{array}$ & $0.177(0.149)$ & $0.224(0.309)$ & $-0.0879(0.319)$ & & \\
\hline $\begin{array}{l}\text { FIXED EFFECTS } \\
\text { THETA } \\
\text { EQUALITY OF } \\
\text { COEFFICIENTS }\end{array}$ & $\begin{array}{r}0.46 \\
\chi^{2}(\mathrm{df}=\end{array}$ & $\begin{array}{l}\text { Yes } \\
* *(0.117) \\
6)=789.064\end{array}$ & $\begin{array}{r}0.465 \\
\chi^{2}(\mathrm{df}=3\end{array}$ & $\begin{array}{l}\text { (s) } \\
=61272) \\
=6151.905\end{array}$ & $\begin{array}{r}0.1 \\
\chi^{2}(\mathrm{df}=?\end{array}$ & $\begin{array}{l}\text { es } \\
(0.131) \\
=4870.295\end{array}$ \\
\hline
\end{tabular}

Notes. $\mathrm{n}=1,121$. Coefficients from bivariate ordered response frameworks (Model 4) and bivariate binary response framework (Models 5 and 6).

Figures in brackets are robust standard errors clustered by (home) team. $* * * \mathrm{p}<0.01, * * \mathrm{p}<0.05,{ }^{*} \mathrm{p}<0.1$ 